\title{
Assessing adherence factors in patients under topical treatment: development of the Topical Therapy Adherence Questionnaire (TTAQ)
}

\author{
Ina Zschocke • Ulrich Mrowietz • Annett Lotzin • \\ Eleni Karakasili $\cdot$ Kristian Reich
}

Received: 25 April 2013/Revised: 16 January 2014/ Accepted: 20 January 2014/Published online: 8 February 2014

(C) The Author(s) 2014. This article is published with open access at Springerlink.com

\begin{abstract}
Medication adherence rates strongly depend on favorable disease outcomes. It is known that medication adherence rates are lower for topical treatment than for systemic treatment. However, to date no validated instrument for the assessment of adherence factors in topical treatment is available. The aim of this study was to develop a new questionnaire to assess adherence risk factors in topical treatment. The development of the Topical Therapy Adherence Questionnaire (TTAQ) and Patient Preference Questionnaire (PPQ) was based on a systematic literature review, and qualitative patient focus interviews and expert focus groups' input. The psychometric properties and comprehensibility of the TTAQ and PPQ were assessed in a feasibility study with 59 psoriasis patients. Our first preliminary results indicate that the TTAQ and PPQ are psychometrically sound and reliable measures for the assessment of factors influencing topical treatment adherence. The questionnaires are currently being further developed and various parameters (e.g., time point of assessment) are currently being tested in an exploratory
\end{abstract}

Electronic supplementary material The online version of this article (doi:10.1007/s00403-014-1446-x) contains supplementary material, which is available to authorized users.

I. Zschocke · A. Lotzin · E. Karakasili

SCIderm GmbH, Drehbahn 1-3, 20354 Hamburg, Germany

U. Mrowietz

Department of Dermatology, Psoriasis-Center,

University Medical Center Schleswig-Holstein,

Schittenhelmstraße. 7, 24105 Kiel, Germany

K. Reich $(\bowtie)$

Dermatologikum Hamburg, Stephansplatz 5,

20354 Hamburg, Germany

e-mail: reich@dermatologikum.de pilot study with ca. 2,000 psoriasis patients receiving topical treatment in a European clinical trial. The use of the final versions of TTAQ and PPQ in clinical practice may facilitate the early identification of specific non-adherence factors in patients under topical treatment, which could enable designing and applying adherence-enhancing interventions according to the patient's individual needs.

Keywords Topical therapy - Compliance · Adherence · Psoriasis · Questionnaire · TTAQ

\section{Introduction}

The WHO defines adherence to treatment as "the extent to which a person's behavior-taking medication, following a diet, and/or executing lifestyle changes-corresponds with agreed recommendations from a health care provider." [43] For the past three decades the importance of adherence has been recognized and proposed as a key factor in achieving the therapeutic goals of medical care [16]. The phrase of C. Everett Koop “Drugs don't work in patients who don't take them" [13] highlights the interaction and close relationship between patient adherence and desired treatment outcome [14]. A meta-analysis of 63 studies revealed that adherence reduces the risk for none or poor treatment outcomes by $26 \%$ and increases threefold the probability of a good treatment outcome [16]. Importantly, poor medication adherence compromises safety and effectiveness of treatment, leads to increased morbidity and death and to increased direct and indirect costs for the health-care system $[13,15,30,35,38]$.

According to its 2003 report the WHO considers adherence rates in developed countries to average only to about $50 \%$ [43]. Within the last three decades a number of 
studies have reported that as many as $40 \%$ of the patients fail to adhere to treatment recommendations while the percentage of non-adherent patients increases to $70 \%$ when treatment regimens are too complicated and/or require lifestyle changes and modification of existing habits (reviewed in [34]). Patients with acute conditions are reported to be more adherent than the ones with chronic conditions whose persistence is very low and is markedly reduced after the first 6 months of treatment [38].

A number of factors have been identified as influencing long-term medication adherence such as the complexity, duration and cost of the treatment, condition characteristics (chronicity, severity, complicating factors), immediacy of beneficial or adverse effects, communication and information flow between the patient and the physician, socio-economic variables (health literacy, substance use disorders), concomitant multiple medication, patients' beliefs on the necessity of the treatment as well as patients' previous treatment experiences and expectancies from and satisfaction with the current treatment $[10,13$, 28, 29].

Adherence to topical treatment has been found challenging since application of topical medications is often considered and reported by the patients as being more difficult than simply taking a pill [20]. Therefore, when assessing topical treatment adherence one has to consider additional specific aspects such as the cosmetic and galenic properties (very greasy, desiccating or sticky vehicles) and the smell of the preparation, the time required for its application as well as the convenience of application [4]. It is therefore not surprising that patients commonly consider topical treatment as unpleasant and time consuming and are commonly reporting their nonadherence to the recommended treatment [32]. However, non-adherence seems to be an even greater problem than patients would like to admit since electronic monitoring of patients' controlled adherence behavior reveals that patients tend to overstate their use of medication and hence their adherence in treatment logs [20, 32]. In general, topical treatment adherence for dermatological conditions is poor, with primary adherence-prescription redemption-being only $65 \%$ (for psoriasis patients primary adherence is $50 \%$ ) and secondary adherence-following prescribed treatment-ranging from 50 to $60 \%$ $[4,20,45]$.

In spite of these increased reported topical treatment non-adherence rates, only a few studies have attempted to investigate and identify why patients with dermatologic conditions fail to follow topical medication recommendations [12].

To date there is no reliable self-reporting tool for assessing adherence-influencing factors in patients under topical treatment. The primary goal of this study was to develop a novel tool termed Topical Therapy Adherence Questionnaire (TTAQ) which could allow physicians to identify potential factors for non-adherent behaviors at an early stage thus enabling the application of adherenceenhancing interventions according to each patient's individual needs. Additionally, this study aimed at assessing the psychometric properties, comprehensibility and feasibility of the preliminary version of the TTAQ in a feasibility check with psoriatic patients under topical treatment.

\section{Methods}

A schematic representation of the methodology for the development, initial feasibility check and future evaluation of the TTAQ and the Patient Preference Adherence Questionnaire (PPQ) is illustrated in Fig. 1.

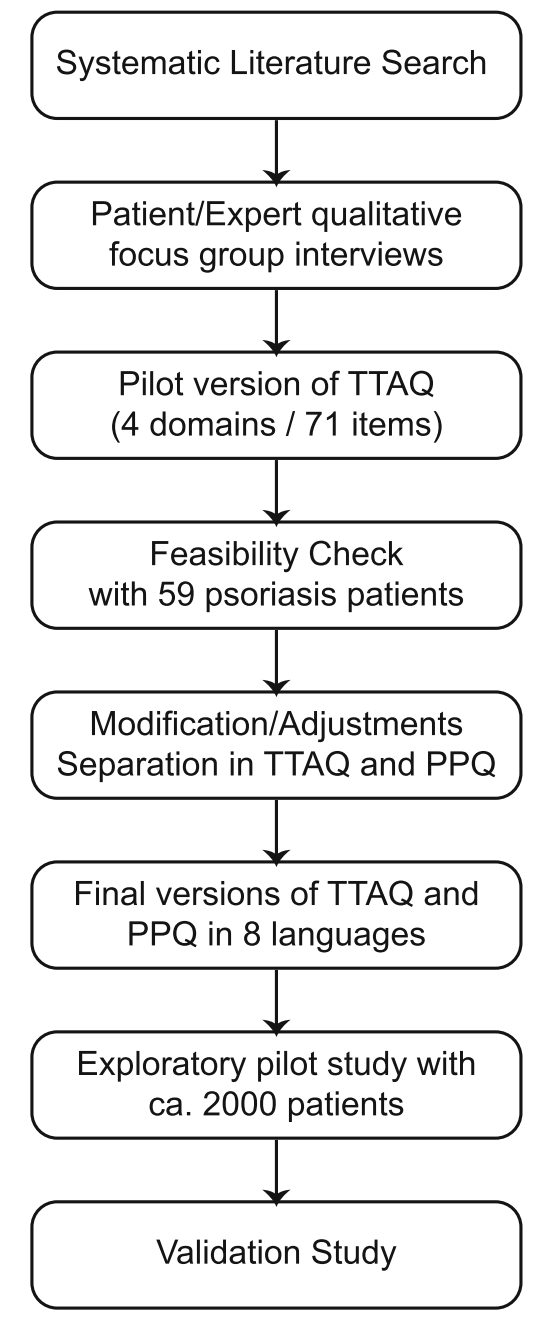

Fig. 1 Development steps of the TTAQ and PPQ questionnaires 
Development of the item pool

In order to ensure the content validity for the newly developed tool, an extensive literature search in combination with qualitative interviews with patient and expert focus groups was performed.

\section{Literature search}

A systematic literature search of the Medline database was conducted in January and February of 2011. The aim was to identify existing self-reporting tools, i.e., tools used as patient reported outcomes for the assessment of aspects known/expected to influence adherence. Tools which assessed patient treatment satisfaction, quality of life and general health status were included in the search protocol as it has been shown that all these areas might influence treatment adherence $[18,30]$. The first search strategy included occurrences for QoL and treatment satisfaction including existing questionnaires known to the authors [(c(()(()(((Quality of life OR QoL OR Quality of life measurements OR Quality of life assessment) OR Quality of Life [Mesh]) OR euroqol eq-5d) OR sf-36) OR treatment satisfaction questionnaire) OR FLQA) OR DLQI) OR Skindex) OR PDI) OR psoriasis disability index) OR patient benefit index) AND ((validation) OR validity) OR reliability) AND psoriasis)], which provided 83 hits. Furthermore, the second search strategy included occurrences for adherence/non-adherence in combination with dermatology and topical treatment [((( (predictor*) OR factor*) AND (((complian*) OR non-complian*) OR adheren*) OR non-adheren*) AND ((((topic* therap*) OR topic* treatment*) OR dermatol* treatment*) OR dermatol* therap*)], which provided 40 hits. Citation titles, index terms, and abstracts from both searches were screened to identify potentially relevant articles containing or describing already existing tools, which were subsequently retrieved for full-text review $[1-3,5-9,11,12,17,19,21-27,31,36$, $39-42,44,46]$.

Patient qualitative focus group interviews

In order to include all relevant aspects, needs and views of psoriasis patients, qualitative focus group interviews were conducted in February and March 2011, one with a national $[4$ (3 men and 1 woman) members of the German Patient's Psoriasis Association-Deutscher Psoriasis Bund e.V] and an international [6 members (2 from Germany, 1 each from Spain, Denmark, Sweden, and The Netherlands) of the European Federation of Psoriasis Patient Organization-EUROPSO] patient advisory board. Patients participating in the interviews were selected according to their experience with topical treatment and in general with managing psoriasis and not according to their psoriasis condition. The aim was to have a representative population as the TTAQ questionnaire could be used for assessing adherence-influencing factors in all patients under topical treatments. Guided by an interviewer, participants were asked to give their feedback on the following topics: "important characteristics to be satisfied with topical treatment", e.g., efficacy of treatment, side effects, "criteria to judge a topical treatment as practicable", e.g., galenic and cosmetic properties, time expenditure required for application, how often should the medication be applied, "important factors for the appraisal of the value of a topical treatment", e.g., expectations regarding the effect of the treatment, immediacy of beneficial effects and "important factors for being adherent with a prescribed topical treatment", e.g., information received regarding the treatment and its correct application, recollection of this information, frequency of visits to the physician.

Expert qualitative focus groups

A total of 11 experts from the fields of dermatology (7), psychology (1), health economic (1) and clinical research (2) were invited to participate in an expert panel meeting in April 2011. The corresponding experts reviewed each item of the developed item pool, identified via the literature search and confirmed during the patient interviews, and its relevance and suitability was evaluated for inclusion or exclusion from the newly developed TTAQ.

\section{TTAQ feasibility check}

The 71-item containing TTAQ was initially assessed in a feasibility check with $n=59$ psoriasis patients who were selected from different sites and who used topical treatments for psoriasis. The draft version of the questionnaire was sent to the patients along with a cover letter explaining them the scope for the development of this questionnaire and that their feedback is requested in order to perform an initial feasibility check and importantly to assess the comprehensibility of the items. Patients were asked to answer the TTAQ and to comment on the comprehensibility and relevance of the TTAQ items on a separate sheet. Patients were requested to fill-out the questionnaire anonymously and send it back to the authors per post. Item characteristics were analyzed descriptively by computing mean, standard deviation, range, skewness and kurtosis. Item difficulty and item-total correlation were also calculated for all items. Reliability of the TTAQ scales was assessed by computing internal consistencies (Cronbachs's $\alpha)$ over all items. 


\section{Results}

Literature search

Sixteen assessment tools were identified which were generic, dermatology specific or psoriasis specific. Out of these tools, 11 were considered as relevant to our research aims: the EuroQOL 5D [8], the Freiburg Life Quality Assessment (FLQA) [46], the Short Form 36 (SF36) and Short Form 12 (SF12) [11], the Dermatology Life Quality Index (DLQI) [23], the Skindex [7], the Treatment Satisfaction Questionnaire for Medication (TSQM) [2], the Psoriasis Disability Index (PDI) [11], the Patient Benefit Index (PBI) [6], the Belief and Behavior Questionnaire (BBQ) [16], the Brief Medication Questionnaire [33] and the Medication Adherence SelfReport Inventory (MASRI) [34]. These tools assessed either adherence-influencing factors or treatment satisfaction in patients under medication, or disease related or general quality of life in dermatological diseases or in psoriasis. In summary, these tools addressed the following areas: psyche, pain, symptoms, side effects, everyday coping, mobility, self assessment/health status treatment evaluation, overall satisfaction/condition, professional- and social life, choice of clothing, sports/leisure, love-life, satisfaction efficacy medication, satisfaction symptom relief, satisfaction time required, special questions regarding side effects, overall satisfaction medication, valuation/trust in medication, risk-benefit assessment, benefit assessment of treatment, cost of treatment and effect of treatment. After a careful examination, consideration and discussion of these constructs, the following domains were decided by the authors to be included in the newly developed TTAQ and to be placed under discussion by the qualitative patient and expert focus interviews: "Patient's benefit from treatment", "Knowledge, communication and relationship with the physician" and "Patient preference and satisfaction with the treatment". The items within the domains "Patient's benefit from treatment" and "Patient preference and satisfaction with treatment" were created with a special focus on topical treatment while the ones within the domain "Knowledge, communication and relationship toward the doctor" assess the quality of the patient-physician relationship as well as the amount of information the patients receive concerning their condition and its treatment with the relationship to the physician. Subsequently, the draft version of the TTAQ was created by formulating items within these domains that aimed at reflecting and assessing topical treatment adherence-influencing factors.

Patient qualitative focus group interviews

The later analysis of all items collected and discussed during these interviews revealed that all aspects reported by the patients were already mentioned in the relevant literature and included in the item pool that had been created from the literature search.

Expert qualitative focus groups

No relevant changes to the presented items were deemed necessary.

\section{TTAQ construction}

A total of 71 items were decided to be included into the first version of the TTAQ. The TTAQ included now the four domains "Patient's benefit from treatment", "Knowledge, communication and relationship with the physician", "Patient preference" and "Patient satisfaction with treatment". All items were scaled in a four-point Likert format $(0=$ strongly disagree, $1=$ disagree, $2=$ agree and $3=$ strongly agree), with a supplementary option to tick "Does not apply to me".

\section{TTAQ feasibility check}

Out of 89 patients with psoriasis to whom the TTAQ questionnaire was sent, $59(66.3 \%)$ completed and returned the questionnaire. Sociodemographic and medical baseline data of the patients were not considered.

Out of the 71 four-point ordinal-scaled items, 6 items showed a range lower than 3.00. Difficulties, item-total correlations and selection indices for each item are shown in Suppl. Table 1. Item difficulty should range between $D=$ 0.20 and 0.80 [33]. Two items showed high difficulties $(D<0.20)$, i.e., it was very difficult to reach high values in these items. 14 items showed very low difficulties $(D>0.80)$, i.e., it was very easy to approach high ratings on these items.

The item-total correlation is defined as the correlation of responses to individual items with overall test score without the respective item. The higher the correlation, the more the item results are consistent with the scale as a whole. An insufficient item-total correlation is assumed if the itemtotal correlation $r_{\text {itt }}$ is lower than 0.20 [33]. No item showed an item-total correlation of $r_{\text {itt }}<0.20$. The lowest values showed the items $13\left(r_{\text {itt }}=0.20\right)$ and item $14\left(r_{\text {itt }}=0.26\right)$.

The Mittenecker and Ebel selection criterion $(\mathrm{Sj})$ considers both the item-total correlation and the item difficulty and hence is regarded as a better evaluation criterion than the use of the item difficulty and item-total correlation alone. Items with $\mathrm{Sj}<0.50$ are regarded as less suitable [33]. As seen in Suppl. Table 1, two items (which also showed the lowest item-total correlation) did not reach this criteria $(13, \mathrm{Sj}=0.24$ and $14, \mathrm{Sj}=0.29)$.

Internal consistency was measured by Cronbach's $\alpha$ over all items. All items had Cronbach's $\alpha$ values that were higher than 0.80 and hence were considered as acceptable [25]. 
Table 1 Difficulties, item-total correlations and selection indices of TTAQ and PPQ

\begin{tabular}{lcccc}
\hline $\begin{array}{l}\text { Questionnaire/ } \\
\text { domain }\end{array}$ & $\begin{array}{l}\text { Number } \\
\text { of items }\end{array}$ & Difficulty & $\begin{array}{l}\text { Item-total } \\
\text { correlation }\end{array}$ & $\begin{array}{l}\text { Selection } \\
\text { index }\end{array}$ \\
\hline $\begin{array}{l}\text { TTAQ } \\
\text { Patient benefit }\end{array}$ & 40 & $0.12-0.85$ & $0.42-0.92$ & $0.52-1.10$ \\
$\begin{array}{l}\text { Knowledge, } \\
\text { communication } \\
\text { and relationship } \\
\text { with physician }\end{array}$ & 7 & $0.78-0.86$ & $0.58-0.92$ & $0.82-1.26$ \\
$\begin{array}{l}\text { Satisfaction with } \\
\text { treatment }\end{array}$ & 12 & $0.65-0.85$ & $0.51-0.93$ & $0.64-1.25$ \\
$\begin{array}{l}\text { PPQ } \\
\text { Patient } \\
\text { preferences }\end{array}$ & 10 & $0.63-0.77$ & $0.60-0.97$ & $0.65-1.14$ \\
\hline
\end{tabular}

Adjustments and modifications

From the item analysis, items 13 and 14 were found to be the least suitable; both showed the lowest item-total correlations and did not reach the Mittenecker and Ebel selection criteria. Therefore, both items were omitted from the final version of the questionnaire. In Table 1 the TTAQ and the PPQ domains and the ranges of the difficulty, itemtotal correlation and selection index are depicted.

On the basis of the patients' evaluation on item comprehensibility and suitability, various expressions and wordings were adapted in order to reduce misunderstandings of the items. In addition, items $44-53$ referring to the patient preference domain were decided to form a separate questionnaire (Patient Preference Questionnaire, PPQ, see Appendix 2), because a single assessment of the patient's treatment preference between current and previous treatment seemed to be sufficient, while all the other domains included in the TTAQ should be assessed more than once during the patient's current treatment with a topical medication.

The final version of the TTAQ contained 59 items that were divided into three domains (see Appendix 1). Table 1 shows for each of the four domains the number of all items that were included in the final version of the TTAQ and the PPQ and their range difficulties, item-total correlations and selection indices.

\section{Discussion}

Favorable treatment outcomes are strongly dependent on medication adherence rates [16]. Importantly, it has been reported that adherence for patients in daily clinical practice is significantly different (i.e., lower) than the one observed in a clinical trial setting and hence not all patients benefit from a treatment as might be expected from the results of such clinical trials [18].
Therefore, it is of great importance to have reliable and easy-to-use tools which can be used in clinical practice for assessing predictors of treatment adherence and nonadherence. To date no such a tool exists which is routinely used in clinical practice for assessing topical treatment adherence-influencing factors in patients with dermatologic conditions. Given that dermatological conditions significantly impair the patient's QoL and treatment regimens are often considered as time consuming, complicated and unpleasant, developing a novel tool that could assess these specific conditions and patient-related factors seems to be highly relevant. Additionally, the new tool enables to assess the relationship and information flow between the patient and the physician since this is considered to influence the patient's treatment adherence to a major extent.

Those pillars supported the development of the TTAQ. The first preliminary results of the feasibility check indicate that the TTAQ contains psychometrically sound items which may be reliable for assessing factors of topical treatment adherence.

Importantly, both the TTAQ as well as the PPQ were translated from their German template in a validated way (forth and back translation) in seven languages: Danish, Dutch, English, French, Italian, Spanish and Swedish. Both questionnaires are currently being used in a multicenter randomized, controlled trial with appr. 2,000 psoriasis patients under topical treatment performed in Denmark, France, Germany, Italy, The Netherlands, Spain, Sweden and the UK. Within this pilot exploratory study, both questionnaires will be given to the patients at different time points during their treatment in order to assess when the questionnaires should be used, i.e., prior to starting a treatment or after a definite amount of time. In any case, the final versions of the tools would aim to identify adherence risk factors early on which would then enable the physicians to "predict" non-adherent behaviors from patients as well as the reasons which might lead to such behaviors. For example, if a patient would reply in questions $12-17$ of the TTAQ that the current topical treatment limits his/her activities, then this might serve as a hint for the physician to discuss and address with the patient these issues and potentially even consider different treatment possibilities. Furthermore, following the evaluation of the results from the currently ongoing pilot study the number of items, especially in the TTAQ, will be reconsidered. Since it is aimed that the newly developed tools will be used-once validated-in daily clinical practice, any redundant items will be deleted in order to reduce the time needed to fill-out the questionnaire and hence to increase its practicability. Summarizing the ongoing exploratory study mainly aims to further develop and fine-tune both tools. In accordance with the COSMIN 
taxonomy [37] the following validation criteria will be evaluated either during the currently ongoing exploratory pilot study or at a later time point: internal consistency, reliability, content validity, construct validity (including convergent and discriminant validity, hypotheses testing and cross-cultural validity), criterion validity, and responsiveness.

The aim of the future use of TTAQ in clinical practice is to allow physicians to identify potential factors for nonadherence at an early time point and to enable them in that way to apply adherence-enhancing interventions according to patient's individual needs.

Acknowledgments We thank LEO Pharma A/S, Ballerup, Denmark, for the financial support of the project.
Conflict of interest Ulrich Mrowietz has been an advisor and/or received speaker's honoraria and/or received grants and/or participated in clinical trials of the following companies: Abbott, AbbVie, AlmirallHermal, Amgen, BASF, Biogen-Idec, Celgene, Centocor, Eli Lilly, Forward Pharma, Galderma, Janssen, LEO Pharma, Medac, MSD, Miltenyi Biotech, Novartis, Pfizer, Teva, VBL and Xenoport.Kristian Reich has received honoraria as consultant and/or advisory board member and/or acted as paid speaker and/or participated in clinical trials sponsored by Abbott, AbbVie, Amgen, Basilea, Biogen-Idec, Celgene, Centocor, Eli Lilly, Forward Pharma, GlaxoSmithKline, Janssen-Cilag, LEO Pharma, Medac, MSD (Essex Pharma, Schering-Plough), Novartis, Ocean Pharma, Pfizer (Wyeth) and UCB.Ina Zschocke, Annett Lotzin and Eleni Karakasili declare that they have no conflict of interest.

Open Access This article is distributed under the terms of the Creative Commons Attribution License which permits any use, distribution, and reproduction in any medium, provided the original author(s) and the source are credited.

\section{Appendix 1}

Final English Version of TTAQ

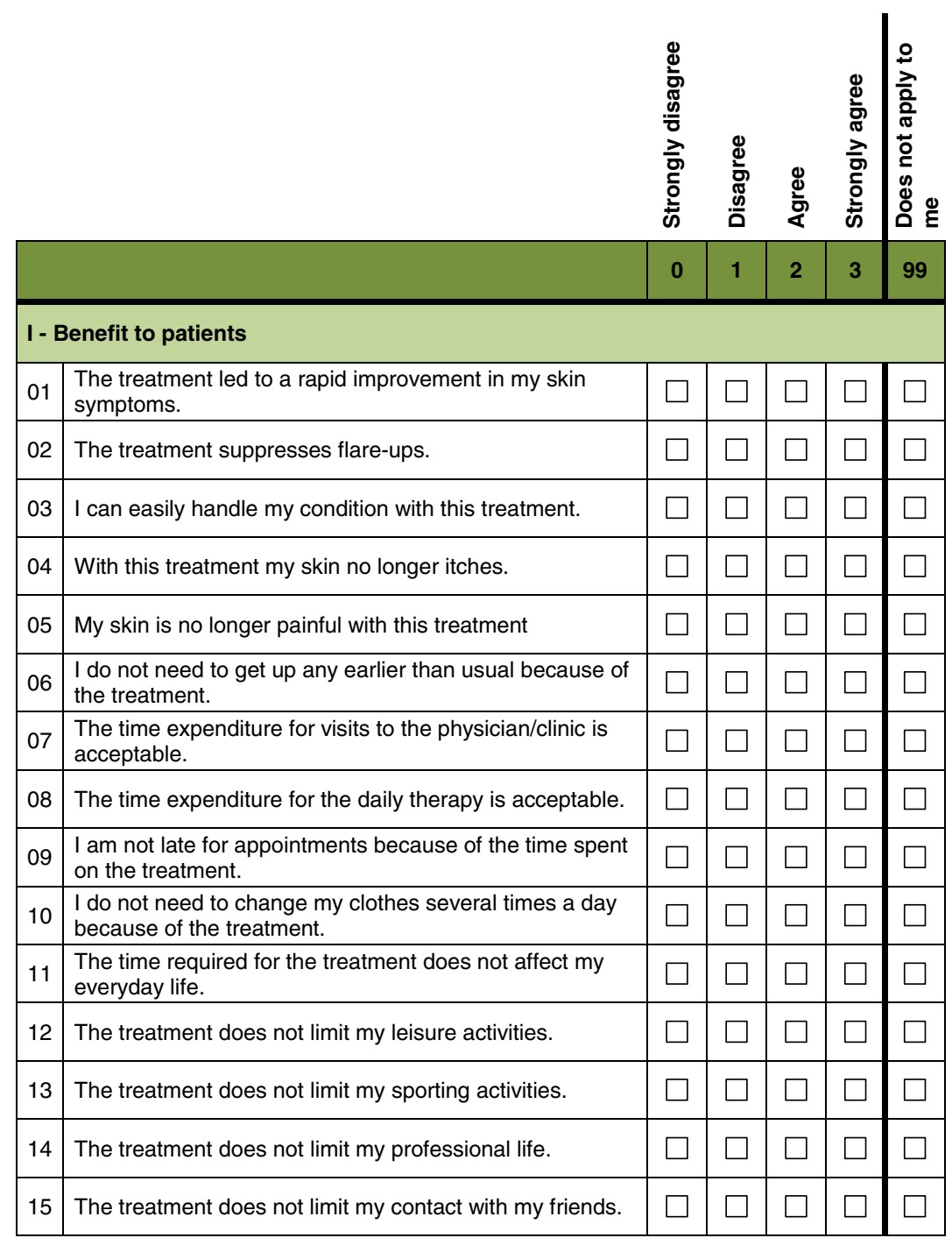




\begin{tabular}{|c|c|c|c|c|c|c|}
\hline & & 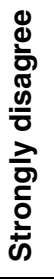 & 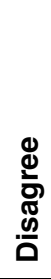 & 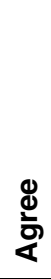 & 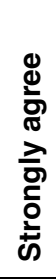 & 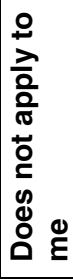 \\
\hline & & 0 & 1 & 2 & 3 & 99 \\
\hline 16 & The treatment does not affect my sex life. & $\square$ & $\square$ & $\square$ & $\square$ & $\square$ \\
\hline 17 & The treatment does not limit my general well-being. & $\square$ & $\square$ & $\square$ & $\square$ & $\square$ \\
\hline 18 & I am more confident as a result of the treatment. & $\square$ & $\square$ & $\square$ & $\square$ & $\square$ \\
\hline 19 & I am enjoying life again as a result of the treatment. & $\square$ & $\square$ & $\square$ & $\square$ & $\square$ \\
\hline 20 & $\begin{array}{l}\text { As a result of the treatment, I am not worried that my skin } \\
\text { condition will get worse. }\end{array}$ & $\square$ & $\square$ & $\square$ & $\square$ & $\square$ \\
\hline 21 & $\begin{array}{l}\text { All visible skin symptoms have more or less disappeared } \\
\text { thanks to the treatment. }\end{array}$ & $\square$ & $\square$ & $\square$ & $\square$ & $\square$ \\
\hline 22 & $\begin{array}{l}\text { I consider the improvement in the condition of my skin to } \\
\text { be acceptable. }\end{array}$ & $\square$ & $\square$ & $\square$ & $\square$ & $\square$ \\
\hline 23 & The treatment has met my expectations. & $\square$ & $\square$ & $\square$ & $\square$ & $\square$ \\
\hline 24 & My personal treatment goals have been met. & $\square$ & $\square$ & $\square$ & $\square$ & $\square$ \\
\hline 25 & The side effects of the treatment were acceptable & $\square$ & $\square$ & $\square$ & $\square$ & $\square$ \\
\hline 26 & $\begin{array}{l}\text { The positive aspects of the treatment outweigh the } \\
\text { negative ones. }\end{array}$ & $\square$ & $\square$ & $\square$ & $\square$ & $\mathrm{L}$ \\
\hline 27 & The preparation is easy to use. & $\square$ & $\square$ & $\square$ & $\square$ & L \\
\hline 28 & $\begin{array}{l}\text { The preparation is also easy to apply in extreme } \\
\text { temperatures. }\end{array}$ & $\square$ & $\square$ & $\square$ & $\square$ & 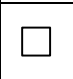 \\
\hline 29 & The preparation is easy to apply during travel. & $\square$ & $\square$ & $\square$ & $\square$ & - \\
\hline 30 & The preparation is easy to dispense. & $\square$ & $\square$ & $\square$ & $\square$ & - \\
\hline 31 & The tube/bottle is easy to open and close. & $\square$ & $\square$ & $\square$ & $\square$ & - \\
\hline 32 & The tube/bottle is easy to empty. & $\square$ & $\square$ & $\square$ & $\square$ & $\square$ \\
\hline 33 & $\begin{array}{l}\text { The strength of the bottle/tube makes it suitable for daily } \\
\text { use. }\end{array}$ & $\square$ & $\square$ & $\square$ & $\square$ & 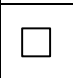 \\
\hline 34 & The preparation leaves no residues on my skin. & $\square$ & $\square$ & $\square$ & $\square$ & $\square$ \\
\hline
\end{tabular}




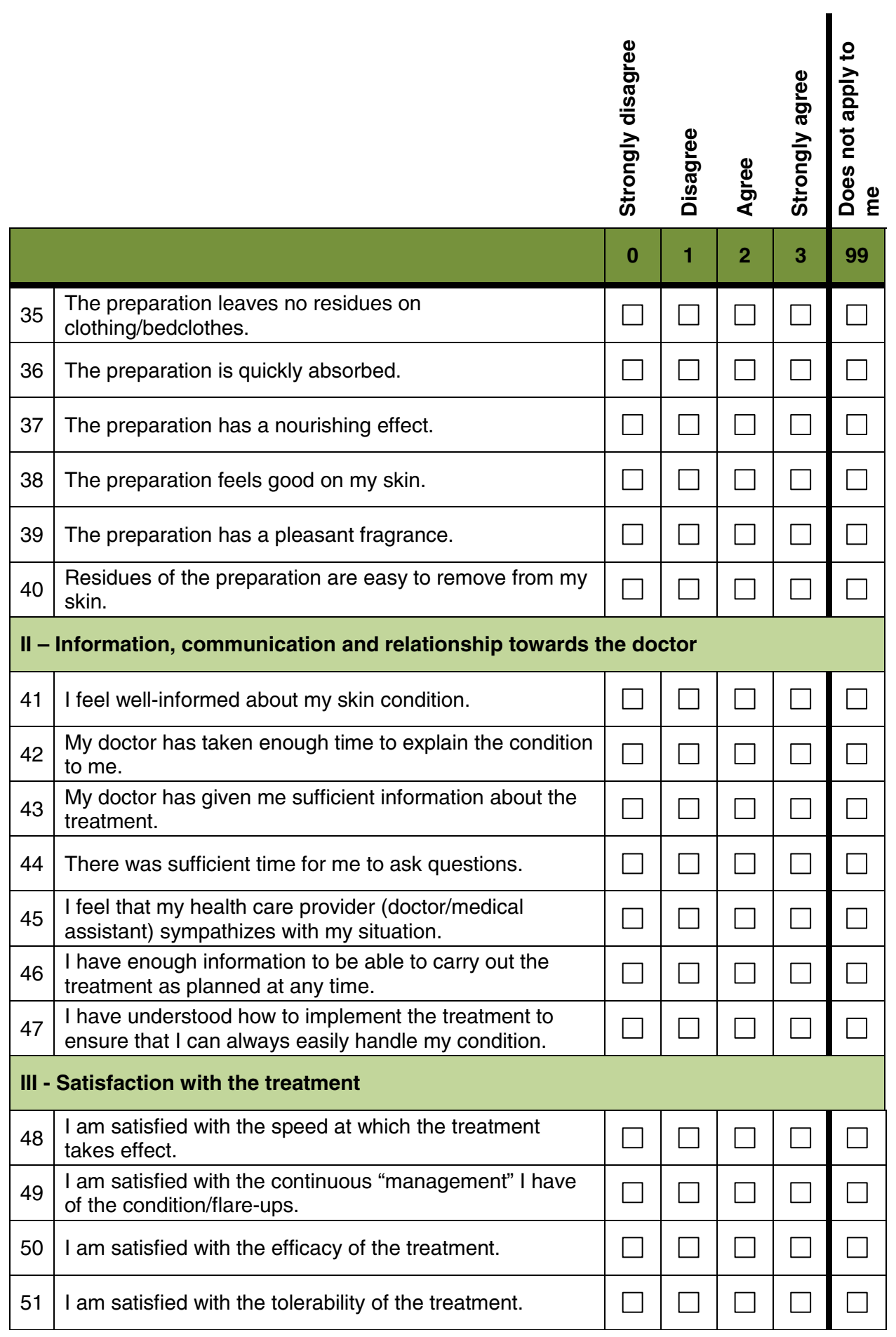




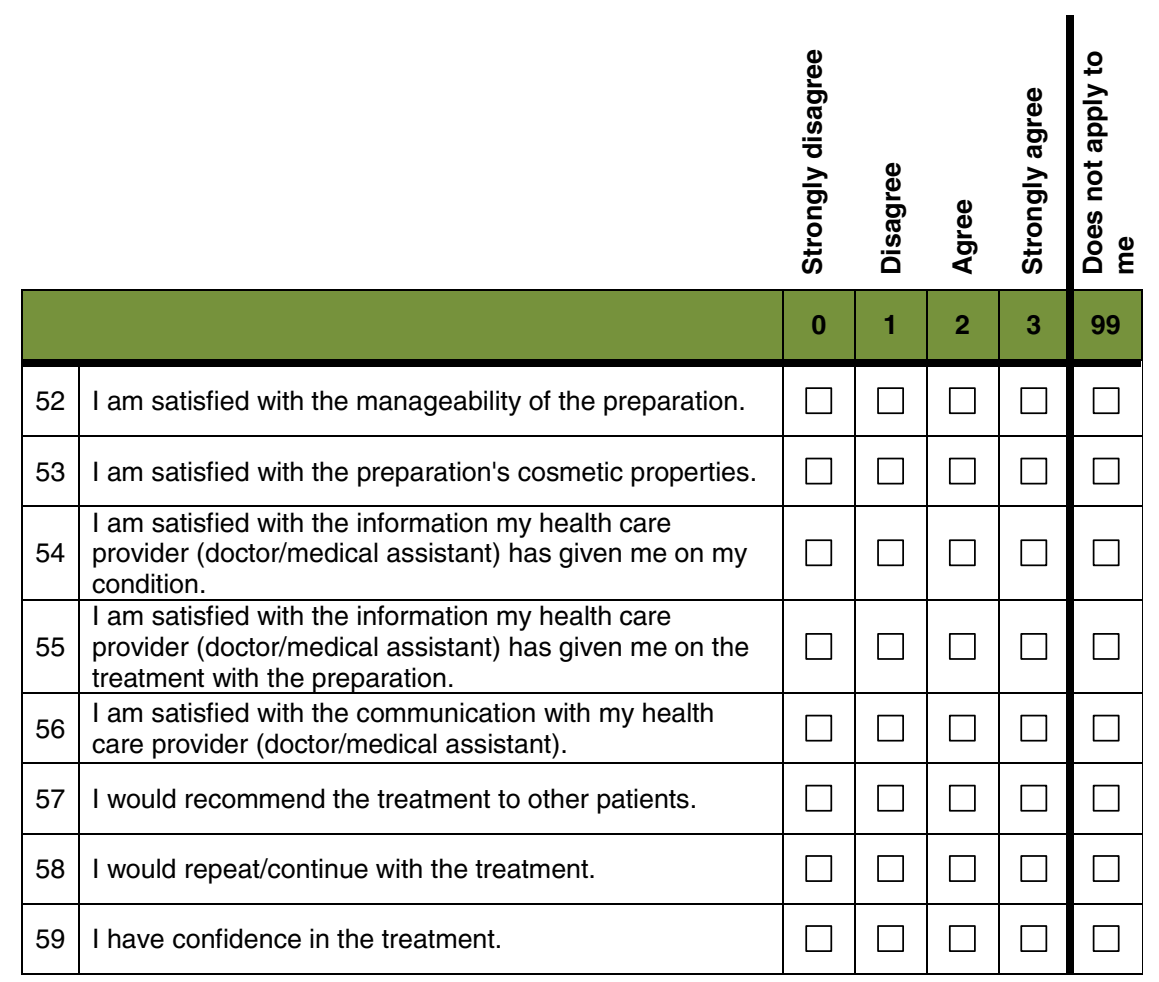

\section{Appendix 2}

Final English Version of PPQ

\begin{tabular}{|c|c|c|c|c|c|c|}
\hline & \multirow[t]{2}{*}{ 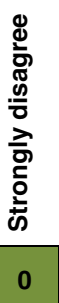 } & \multirow{2}{*}{ 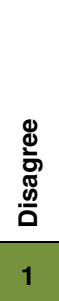 } & \multirow{2}{*}{$\begin{array}{l}\frac{\Phi}{5} \\
\frac{5}{4} \\
2\end{array}$} & \multirow{2}{*}{ 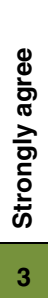 } & \multirow[t]{2}{*}{ 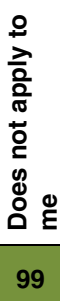 } \\
\hline & & & & & & \\
\hline 01 & $\begin{array}{l}\text { The current treatment is more effective than the previous } \\
\text { topical treatments. }\end{array}$ & $\square$ & $\square$ & $\square$ & $\square$ & $\square$ \\
\hline 02 & $\begin{array}{l}\text { The current treatment is easier to use than the previous } \\
\text { topical treatments. }\end{array}$ & $\square$ & $\square$ & $\square$ & $\square$ & $\square$ \\
\hline 03 & $\begin{array}{l}\text { The current treatment has fewer side effects than the } \\
\text { previous topical treatments. }\end{array}$ & $\square$ & $\square$ & $\square$ & $\square$ & $\square$ \\
\hline 04 & $\begin{array}{l}\text { I consider the current treatment to be better tolerable } \\
\text { than the previous topical treatments. }\end{array}$ & $\square$ & $\square$ & $\square$ & $\square$ & $\square$ \\
\hline 05 & $\begin{array}{l}\text { I prefer the current treatment to previous topical } \\
\text { treatments. }\end{array}$ & $\square$ & $\square$ & $\square$ & $\square$ & $\square$ \\
\hline 06 & $\begin{array}{l}\text { The current treatment is more effective than previous } \\
\text { systemic treatments. }\end{array}$ & $\square$ & $\square$ & $\square$ & $\square$ & $\square$ \\
\hline 07 & $\begin{array}{l}\text { The current treatment is easier to use than previous } \\
\text { systemic treatments. }\end{array}$ & $\square$ & $\square$ & $\square$ & $\square$ & $\square$ \\
\hline 08 & $\begin{array}{l}\text { The current treatment has fewer side effects than } \\
\text { previous systemic treatments. }\end{array}$ & $\square$ & $\square$ & $\square$ & $\square$ & $\square$ \\
\hline 09 & $\begin{array}{l}\text { I consider the current treatment to be better tolerated } \\
\text { than previous systemic treatments. }\end{array}$ & $\square$ & $\square$ & $\square$ & $\square$ & $\square$ \\
\hline 10 & $\begin{array}{l}\text { I prefer the current treatment to previous systemic } \\
\text { treatments. }\end{array}$ & $\square$ & $\square$ & $\square$ & $\square$ & $\square$ \\
\hline
\end{tabular}




\section{References}

1. Ashcroft DM, Li Wan PA, Williams HC, Griffiths CE (1998) Quality of life measures in psoriasis: a critical appraisal of their quality. J Clin Pharm Ther 23:391-398

2. Atkinson MJ, Sinha A, Hass SL, Colman SS, Kumar RN, Brod M, Rowland CR (2004) Validation of a general measure of treatment satisfaction, the Treatment Satisfaction Questionnaire for Medication (TSQM), using a national panel study of chronic disease. Health Qual Life Outcomes 2:12

3. Augustin M, Dieterle W, Zschocke I, Brill C, Trefzer D, Peschen M, Schopf E, Vanscheidt W (1997) Development and validation of a disease-specific questionnaire on the quality of life of patients with chronic venous insufficiency. Vasa 26:291-301

4. Augustin M, Holland B, Dartsch D, Langenbruch A, Radtke MA (2011) Adherence in the treatment of psoriasis: a systematic review. Dermatology 222:363-374

5. Augustin M, Lange S, Wenninger K, Seidenglanz K, Amon U, Zschocke I (2004) Validation of a comprehensive Freiburg Life Quality Assessment (FLQA) core questionnaire and development of a threshold system. Eur J Dermatol 14:107-113

6. Augustin M, Radtke MA, Zschocke I, Blome C, Behechtnejad J, Schafer I, Reusch M, Mielke V, Rustenbach SJ (2009) The patient benefit index: a novel approach in patient-defined outcomes measurement for skin diseases. Arch Dermatol Res 301:561-571

7. Augustin M, Wenninger K, Amon U, Schroth MJ, Kuster W, Chren M, Kupfer J, Gieler U (2004) German adaptation of the Skindex-29 questionnaire on quality of life in dermatology: validation and clinical results. Dermatology 209:14-20

8. Barton GR, Hodgekins J, Mugford M, Jones PB, Croudace T, Fowler D (2009) Measuring the benefits of treatment for psychosis: validity and responsiveness of the EQ-5D. Br J Psychiatry 195:170-177

9. Bewley A, Page B (2011) Maximizing patient adherence for optimal outcomes in psoriasis. J Eur Acad Dermatol Venereol 25:9-14

10. Brawley LR, Culos-Reed SN (2000) Studying adherence to therapeutic regimens: overview, theories, recommendations. Control Clin Trials 21:156S-163S

11. Bronsard V, Paul C, Prey S, Puzenat E, Gourraud PA, Aractingi S, Aubin F, Bagot M, Cribier B, Joly P, Jullien D, Le MM, Richard-Lallemand MA, Ortonne JP (2010) What are the best outcome measures for assessing quality of life in plaque type psoriasis? A systematic review of the literature. J Eur Acad Dermatol Venereol 24(Suppl 2):17-22

12. Brown KK, Wingfield ER, Kimball AB (2006) Determining the relative importance of patient motivations for nonadherence to topical corticosteroid therapy in psoriasis. J Am Acad Dermatol 55:607-613

13. Brown MT, Bussell JK (2011) Medication adherence: WHO cares? Mayo Clin Proc 86:304-314

14. Bryant LJ (2011) Medicines adherence-evidence for any intervention is disappointing. J Prim Health Care 3:240-243

15. Butler RJ, Davis TK, Johnson WG, Gardner HH (2011) Effects of nonadherence with prescription drugs among older adults. Am J Manag Care 17:153-160

16. Dimatteo MR, Giordani PJ, Lepper HS, Croghan TW (2002) Patient adherence and medical treatment outcomes: a meta-analysis. Med Care 40:794-811

17. Dreno B, Thiboutot D, Gollnick H, Finlay AY, Layton A, Leyden JJ, Leutenegger E, Perez M (2010) Large-scale worldwide observational study of adherence with acne therapy. Int J Dermatol 49:448-456

18. Epstein RS (2011) Medication adherence: hope for improvement? Mayo Clin Proc 86:268-270
19. Ersser SJ, Cowdell FC, Latter SM, Healy E (2010) Self-management experiences in adults with mild-moderate psoriasis: an exploratory study and implications for improved support. Br J Dermatol 163:1044-1049

20. Feldman SR, Camacho FT, Krejci-Manwaring J, Carroll CL, Balkrishnan R (2007) Adherence to topical therapy increases around the time of office visits. J Am Acad Dermatol 57:81-83

21. Feldman SR, Horn EJ, Balkrishnan R, Basra MK, Finlay AY, McCoy D, Menter A, van de Kerkhof PC (2008) Psoriasis: improving adherence to topical therapy. J Am Acad Dermatol 59:1009-1016

22. Finlay AY, Kelly SE (1987) Psoriasis-an index of disability. Clin Exp Dermatol 12:8-11

23. Finlay AY, Khan GK (1994) Dermatology Life Quality Index (DLQI) - a simple practical measure for routine clinical use. Clin Exp Dermatol 19:210-216

24. Flowers B, Wand M, Piltz-Seymour J, Berke SJ, Day D, Teague J, Smoot TM, Landry TA, Bergamini MV, Mallick S (2006) Patients' and physicians' perceptions of the travoprost dosing aid: an open-label, multicenter study of adherence with prostaglandin analogue therapy for open-angle glaucoma or ocular hypertension. Clin Ther 28:1803-1811

25. Greenlaw SM, Yentzer BA, O’Neill JL, Balkrishnan R, Feldman SR (2010) Assessing adherence to dermatology treatments: a review of self-report and electronic measures. Skin Res Technol $16: 253-258$

26. Gupta G, Mallefet P, Kress DW, Sergeant A (2009) Adherence to topical dermatological therapy: lessons from oral drug treatment. Br J Dermatol 161:221-227

27. Hodari KT, Nanton JR, Carroll CL, Feldman SR, Balkrishnan R (2006) Adherence in dermatology: a review of the last 20 years. J Dermatol Treat 17:136-142

28. Hovstadius B, Petersson G (2011) Non-adherence to drug therapy and drug acquisition costs in a national population-a patientbased register study. BMC Health Serv Res 11:326 326

29. Ingersoll KS, Cohen J (2008) The impact of medication regimen factors on adherence to chronic treatment: a review of literature. J Behav Med 31:213-224

30. Jank S, Bertsche T, Schellberg D, Herzog W, Haefeli WE (2009) The A14-scale: development and evaluation of a questionnaire for assessment of adherence and individual barriers. Pharm World Sci 31:426-431

31. Kjellgren KI, Ring L, Lindblad A, Maroti M, Serup J (2004) To follow dermatological treatment regimens-patients' and providers' views. Acta Derm Venereol 84:445-450

32. Krejci-Manwaring J, Tusa MG, Carroll C, Camacho F, Kaur M, Carr D, Fleischer AB Jr, Balkrishnan R, Feldman SR (2007) Stealth monitoring of adherence to topical medication: adherence is very poor in children with atopic dermatitis. J Am Acad Dermatol 56:211-216

33. Lienert G (1969) Testaufbau und Testanalyse. Verlag Julius Beltz, Weinheim, Berlin, Basel

34. Martin LR, Williams SL, Haskard KB, Dimatteo MR (2005) The challenge of patient adherence. Ther Clin Risk Manag 1:189-199

35. Matsui D (2009) Strategies to measure and improve patient adherence in clinical trials. Pharm Med 23:289-297

36. McKenna SP, Cook SA, Whalley D, Doward LC, Richards HL, Griffiths CE, Van AD (2003) Development of the PSORIQoL, a psoriasis-specific measure of quality of life designed for use in clinical practice and trials. Br J Dermatol 149:323-331

37. Mokkink LB, Terwee CB, Knol DL, Stratford PW, Alonso J, Patrick DL, Bouter LM, de Vet HC (2006) Protocol of the COSMIN study: COnsensus-based standards for the selection of health measurement INstruments. BMC Med Res Methodol 6:2 
38. Osterberg L, Blaschke T (2005) Adherence to medication. N Engl J Med 353:487-497

39. Picardi A, Pasquini P (2007) Toward a biopsychosocial approach to skin diseases. Adv Psychosom Med 28:109-126

40. Rabin R, de Charro F (2001) EQ-5D: a measure of health status from the EuroQol Group. Ann Med 33:337-343

41. Renzi C, Picardi A, Abeni D, Agostini E, Baliva G, Pasquini P, Puddu P, Braga M (2002) Association of dissatisfaction with care and psychiatric morbidity with poor treatment compliance. Arch Dermatol 138:337-342

42. Ribera M, Dauden E, Puig L, Briones VG, Herranz JM, Bordas X, Vanaclocha F (2011) Design and validation of a questionnaire to measure treatment satisfaction in patients with moderate-tosevere psoriasis: the NEODERMA study. Actas Dermo-Sifiliográficas 102:28-38
43. Sabaté E (2003) Adherence to long-term therapies-evidence for action, WHO. http://apps.who.int/medicinedocs/pdf/s4883e/s4883e. pdf. Accessed 16 Jan 2014. WHO1-211

44. Schmidt J, Lamprecht F, Wittmann WW (1989) Satisfaction with inpatient management. Development of a questionnaire and initial validity studies. Psychother Psychosom Med Psychol 39:248-255

45. Storm A, Andersen SE, Benfeldt E, Serup J (2008) One in 3 prescriptions are never redeemed: primary nonadherence in an outpatient clinic. J Am Acad Dermatol 59:27-33

46. Zschocke I, Seidenglanz K, Lange S, Schiffler A, Amon U (2000) Validation and clinical results of the FLQA-d, a quality of life questionnaire for patients with chronic skin diseases. Dermatol Psychosom 1:12-17 